\title{
Sensitivity Analysis Model Bus Timetabling Problem by Considering Passenger Ease
}

\author{
Hagni Wijayanti, Fajar Delli Wihartiko, Fitria Virgantari
}

\begin{abstract}
The optimal Model Bus Timetabling Problem (MBTP) is a simplification of bus scheduling cases where a bus departure schedule with the optimal number of trips will be searched. The optimal number of trips is defined by maximizing the profit function of the bus by considering constraints such as the availability of buses, the executing officers, the number of passengers and the travel time. This model was developed by adding the constraints of ease of passengers in remembering the schedule. The model is then modified and completed using the branch and bound algorithm. The result of the sensitivity analysis to the model shows that the addition of bus or employee by the manager will not be directly proportional to the addition of passengers. So the addition of buses and employees is done when passengers increase. In addition, the addition of constraints ease passengers in reading the time table will make the increase in corporate profits with the consequences of decreased levels of passenger comfort. If the company chooses to improve the comfort of passengers it will affect the increase of the company's operational costs.
\end{abstract}

Index Terms: Bus Timetabling Problem, Sensitivity Analysis, Optimization.

\section{INTRODUCTION}

Bus rapid Transit (BRT) is a development of the city bus service to improve services for passengers. Some of these improvements include bus priority, increased certainty and speed of service, and an increase in ticket sales system. In the event of departure to the passenger the transport service provider provides a scheduled departure bus (bus time table) [1] and also their routes [2] to passengers. When the scheduling system has not been managed using a real time system based on current bus positions using GPS [3], the bus schedule making process is a priority that BRT managers must address. Because the scheduling is related to business operations and passenger desire. Essentially, passengers always want convenience for themselves [4] and bus managers always want to improve the quality of service. Based on the results of the survey to Bogor's BRT passengers, one of the features that can be added to the making time table is to consider the ease of passengers in remembering the bus departure schedule. This will help passengers to plan a trip with the bus service.

Some of the related studies in this regard are Cedar et al where the study explains the time table synchronization

Revised Manuscript Received on April 25, 2019.

Hagni Wijayanti, Department of Mathematic, Universitas Pakuan, Indonesia.

Fajar Delli Wihartiko, Department of Computer Science, Universitas Pakuan, Indonesia.

Fitria Virgantari, Department of Mathematic, Universitas Pakuan, Indonesia. problem and making time tables with maximum synchronization. Problems are formulated as mixed integer linear programming and heuristic algorithm development to solve polynomial time problems [5]. Naumov also developed a time table synchronization model using the genetic algorithm by taking objective functions based on passenger waiting time [6]. Chuanjio et al. developed a model to find the optimal headway and conducted sensitivity analysis on the model [7]. Bais et al. in Optimal Schedule Modeling for Public Transport System. Conducting research in India with the aim of improving the efficiency and performance of the transport system through optimal scheduling. The method is done by minimizing passenger waiting time at the bus stop and minimizing the number of buses required. Constraints include load factor, time constraints \& frequency constraints [8]. Wihartiko, et al. create an integer programming model that is solved using a genetic algorithm and obtain a scheduling model with optimum trip[1]. Mayyani et al. create a bus scheduling model based on passenger demand from each passenger generation segment [9]. Ma J et al. has developed a model for Stop planning and $\mathrm{S}$ Timetables of Customized Buses. This model is then solved by improved immune genetic algorithm [10].

Based on some of the above research, it will be developed a model that is done with adjustment of time table results to be easily remembered by passengers. The model is an expansion of the study [1]. Passenger punctuality is the main thing. With a memorable departure schedule by passengers will make it easier for passengers to remember and plan passenger trips.

\section{RESEARCH METHOD}

\section{A. Problem Formulation}

The time table model developed in this paper is a development of [1]. The Model Bus Timetabling Problem by Considering Passenger Ease (MBTP-CPE) is adjusted as follows:

Maximize $z(x)=\sum_{r \in R} \sum_{v \in V_{r}} \sum_{p \in P_{v, r}} c_{r, v, p} . x_{r, v, p}$

Subject To

$$
\begin{aligned}
& k_{e m p} \cdot \frac{q_{e m p}}{2} \leq \sum_{r \in R} \sum_{v \in V_{r}} \sum_{p \in P_{r, v}} T_{r, v, p} k_{r, v} \cdot x_{r, v, p} \leq K_{e m p} \cdot \frac{q_{e m p}}{2} \\
& m_{r, v, p}^{R i t} \leq x_{h, p, r} \leq M_{r, v, p}^{R i t} ; \forall r \in R, \forall v \in V_{r}, \forall p \in P_{r, v}
\end{aligned}
$$




$$
\begin{aligned}
& x_{r, v, p} \geq \frac{q_{r, v, p}^{p s g r}}{k_{L F_{r, v, p}}} ; \forall r \in R, \forall v \in V_{r}, \forall p \in P_{r, v} \\
& x_{r, v, p} \in \mathrm{Z}^{+} \cup\{0\} ; \forall r \in R, \forall v \in V_{r}, \forall p \in P_{r, v} \\
& x_{r, v, p} \ni\left(h_{r, v, p} \in \text { time }_{\text {easy }}\right) ; \forall r \in R, \forall v \in V_{r}, \forall p \in P_{r, v}
\end{aligned}
$$

From the Objective Function (1) states that it will look for the trip number of $\left(x_{r, v, p}\right)$ that maximizes the profit $\left(c_{r, v, p}\right)$, where $r \in R=\{1,2, \ldots, r \mid r \in \mathrm{N}\}$ is a set of routes, paths or corridors that service providers serve; $v \in V=\{1,2, \ldots, v \mid v \in \mathrm{N}, r \in R\}$ is a set of schedule variations applied in a given period of time in a route $r \in R$ and $p \in P=\{1,2, \ldots, p \mid p \in \mathrm{N}, v \in V, r \in R\}$, is a set of partitions or timing divisions of timetables applicable in a schedule variation $v \in V$ and $r \in R$.

Constraint (2) guarantees the entire departure $\left(x_{r, v, p}\right)$ can be served by company employees $\left(K_{e m p} \cdot q_{e m p} / 2\right)$ while still taking into account the minimum work of the

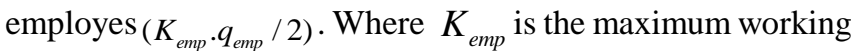
hours of bus operators per day operators plus the maximum overtime hours in minutes for 1 period of variation; $K_{e m p}$ is the minimum working hours of the bus operating officer per day in minutes for 1 period of variation; $q_{\text {emp }}$ is the Number of drivers hired. $T_{r, v, p}$ is the length of the bus trip (minutes) in one trip route to $r \in R$ in the $v \in V_{r}$ schedule variation in the partition to $p \in P_{r, v} . k_{r, v}$ is the number of days of repetition of the schedule during $v \in V_{r}$ on the route $r \in R$.

Constraint (1.3) guarantees that the number of trips served $\left(x_{r, v, p}\right)$ does not exceed the number of trips according to the existing fleet $\left(M_{r, v, p}^{r i t}\right)$ and corresponds to the number of trips in the Standard Minimal Service $\left(m_{r, v, p}^{r i t}\right) . M_{r, v, p}^{r i t}$ the maximum number of trips that must be met for travel on route to $r \in R$ in the variation of the $v \in V_{r}$ schedule on the partition to $p \in P_{r, v}$. In this case $M_{r, v, p}^{r i t}$ is formulated as:

$$
M_{r, v, p}^{r i t}=\frac{\Delta t_{r, v, p}}{h_{r, v, p}}=\frac{t_{r, v, p, n_{\max }}-t_{r, v, p, n_{0}}}{h_{r, v, p}}
$$

Where :

$t_{r, v, p} \quad$ time of departure of the nth buson route to
$r \in R$ in the variation of the $v \in V$ schedule $r \in R$ in the variation of the $v \in V_{r}$ schedule on the partition to $p \in P_{r, v}$

$h_{r, v, p} \quad$ headway bus, is the time difference (minutes) between one departure with the next departure $\left(h_{r, v, p}=t_{r, v, p, n+1}-t_{r, v, p, n}\right)$. In addition headway can be searched using the following equation:

$$
h_{r, v, p}=\frac{2 T_{r, v, p}}{q_{b u s, r}}
$$

$q_{b u s, r} \quad$ the number of fleets that can be operated on route $r \in R$

$m_{r, v, p}^{r i t}$ is the minimum number of trips that may be met for travelon route to $r \in R$ in the variation of the $v \in V_{r}$ schedule on the partition to $p \in P_{r, v}$. In this case $m_{r, v, p}^{r i t}$ is formulated by:

$m_{r, v, p}^{R i t}=\frac{\Delta t_{r, v, p}}{h_{s t d, r, v, p}}$

Where $h_{s t d, r, v, p}$ is a headway based on Minimum Service Standards.

Constraint (4) to ensure that passengers can be served as the company wishes or in this case to ensure that the number of trips $\left(x_{r, v, p}\right)$ exceeds the company's expectations of passengers on each of its carriers $\left(q_{r, v, p}^{p s g r} / k_{L F_{r, v, p}}\right)$. Where $q_{r, v, p}^{p s g r}$ is the average number of passengerson route to $r \in R$ in the variation of the $v \in V_{r}$ schedule on the partition to $p \in P_{r, v}$ and $k_{L F_{r, v, p}}$ the number of passengers the company expects to serveon route to $r \in R$ in the variation of the $v \in V_{r}$ schedule on the partition to $p \in P_{r, v}$. Load Factoris defined as the percentage between the number of passengers and the bus capacity $\left(q_{c t y}\right)$.Constraint (5) ensures that the number of trips generated $\left(x_{r, v, p}\right)$ are nonnegative integers.

Constraint (6) guarantees that the number of trips generated $\left(x_{r, v, p}\right)$ makes the headway value $h_{r, v, p}$ a member of the time-fold set that is easy to remember by passengers $\left(\right.$ time $\left._{\text {easy }}\right)$. In general, a memorable time by passengers is a time in 5-minute increments like 5,10,15 and 20 minutes. However, this time can be adjusted to the needs of passengers.

\section{B. Problem Solution}

The timetable Model (1) cannot be solved directly using the branch and bound algorithm because the constraint (1.6) is a conditional constraint in which a value of $x_{r, v, p}$ which makes $h_{r, v, p}$ has a multiple time which is easy to remember in the set time $e_{\text {easy }}$. It does not include linear equations that can be solved in linear programming. Completion of models with genetic algorithms is possible by modifying the chromosome design according to the set time easy . 
Nevertheless, the genetic algorithm is only capable of providing a solution that is near optimal [1]. On one side of the study [11] shows that the branch and bound algorithm still shows the best performance for the case of bus time tabling problem.

Completion of Model (1) with branch and bound algorithm can be done by modifying Model (1) into integer programming form. Let $f$ be a one-one function that maps the set time $_{\text {easy }}$ to a consecutive positive integer $\left(f:\right.$ time $\left._{\text {easy }} \rightarrow \mathrm{Z}^{+}\right)$. Let $y_{r, v, p}$ be a number of mapping functions $f$ so $h_{r, v, p} \in \mathrm{Z}^{+}$. Here is an illustration of the relationship between variables $x$ (number of trip), $h$ (headway in time $_{\text {easy }}$ ) and $y$. Let $\Delta t=60$ minutes. Suppose the set time $_{\text {easy }}$ used is $\{5,10,15,20\}$. This results in a possible $x$-solution being $\{12,6,4,3\}$ and the corresponding $y$ is $\{1,2,3,4\}$. Since the headway value can be obtained from a time interval divided by the number of trip $\left(h_{r, v, p}=\frac{\Delta t_{r, v, p}}{x_{r, v, p}}\right)$.

Then Model Eqs (1)-(6) can be modified into the following Model Eqs (7)-(11):

Minimize $w(y)=\sum_{r \in R} \sum_{v \in V_{r}} \sum_{p \in P_{v, r}} \frac{y_{r, v, p}}{c_{r, v, p}}$

Subject To

$g_{1}\left(K_{\text {emp }} \cdot \frac{q_{\text {emp }}}{2}\right) \leq \sum_{r \in R} \sum_{v \in V_{r}} \sum_{p \in P_{r, v}} g_{2}\left(y_{r, v, p}\right) \leq g_{1}\left(k_{e m p} \cdot \frac{q_{e m p}}{2}\right)$

$\left[f\left(\frac{\Delta t_{r, v, p}}{M_{r, v, p}^{r i t}}\right)\right] \leq y_{r, v, p} \leq\left[f\left(\frac{\Delta t_{r, v, p}}{M_{r, v, p}^{r i t}}\right)\right] ; \forall r \in R, \forall v \in V_{r}, \forall p \in P_{r, v}$

$y_{r, v, p} \leq\left[f\left(\frac{\Delta t_{r, v, p}}{q_{r, v, p}^{p s g r} / k_{L F_{r, v, p}}}\right)\right] ; \forall r \in R, \forall v \in V_{r}, \forall p \in P_{r, v}$

$1 \leq y_{r, v, p} \in \mathrm{Z}^{+} \leq|Y| ; \forall r \in R, \forall v \in V_{r}, \forall p \in P_{r, v}$

The objective function (7) states that a positive integer corresponding to the headway with minimum inverse gain will be searched. The function $w(x)$ is a helper function to find $y_{r, v, p}$ optimal and does not show the amount of gain obtained. Constraints (8) to ensure solutions are within the employee working span. In this constraint let $g(y)$ be a linear approximation function that maps $\mathrm{y}$ to real numbers so that it corresponds to the required travel time in a route $(r)$, variation $(v)$ and partition $(p)$ of the origin regiony $(g: y \rightarrow \mathrm{R})$. Constraints (9) ensure that the headway obtained is in accordance with the number of available fleets and above the minimum service standards provided. Constraints (10) ensure that the headway obtained is above the company's expectations of passenger conditions. Constraint (10) assures that the resulting solution is an integer of 1 to the number of set members of that number $(|Y|)$.

\section{Timetable Arrangement Algorithm}

Model Eqs (1)-(6) produces a solution of the optimal number of bus trips $\left(x_{r, v, p}^{*}\right)$ and Model Eqs (7)-(11) produces a solution of an integer $\left(y_{r, v, p}^{*}\right)$ corresponding to the optimal headway $\left(h_{r, v, p}^{*}\right)$. Both Model Eqs (1)-(6) and Model Eqs (7)-(11) have not produced a bus departure time table. The bus departure schedule of the optimal number of trips / headways can be made based on the following algorithm:

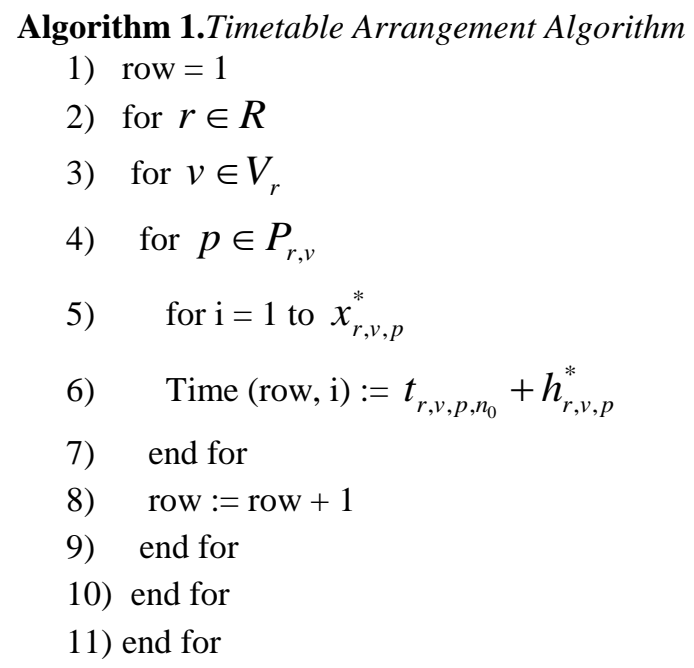

From Algorithm 1 will be generated a Table with the number of different columns that is as much as the value of $x_{r, v, p}^{*}$ and with the number of rows as many as variable $x_{r, v, p}$

\section{Sensitivity Analysis}

The optimal solution in the integer linear programming model is deterministic, but under real conditions, there is always the possibility of change. To anticipate, sensitivity analysis is needed, that is to know the optimum level sensitivity to change each variable involved in the mathematical model. The changes include:

1) Added function constraints.

The addition of a single line of constraints on early mathematical models can occur because management analysts are too simple to formulate the initial problem, the existence of new information or new constraints to be considered.

2) Change of source capacity Sensitivity to change in value is an important review for management because it involves changes in resource capacity. This change in source capacity is often related to certain management decisions, changes in the number of buses, changes in the number of passengers, changes in the number of officers and so on. 


\section{RESUlt AND ANALYSIS}

The optimal time time table model is applied to Bogor's Bus Rapid Transit System. The results of data collection based on company report and survey data in January 2017 are as follows:

1. Bogor's Bus Rapid Transit System has 3 service routes $(R=$ $\{1,2,3\})$ ie Bubulak - Baranang Siang, Baranang Siang Ciawi and Baranang Siang - Sentul City.

2. There are 3 variations of schedule in Bubulak - Baranang Siang route $\left(V_{1}=\{1,2,3\}\right)$ where the first variation is the schedule for Monday - Friday, the second variation is the schedule for Saturday and the third variation is the schedule for Sunday. In addition, there is only one variation of schedule for Baranang Siang - Ciawi and Baranang Siang - Sentul City $\left(V_{2}=\{1\} \& V_{3}=\{1\}\right)$ routes, which means that the schedules on each route are applied for Monday - Sunday.

3. In summary data of the number of partitions for each route variation $\left(p_{r, v}\right)$ along with the bus departure time on each partition, data on the number of buses used, bus travel length, headway, number of passengers, revenue and bus operating costs for each partition can be seen on the following table:

Table 1.Timetable Requirement Data Recapitulation

\begin{tabular}{|c|c|c|c|c|c|c|c|c|c|c|c|c|}
\hline No & $r$ & $v_{r}$ & $p_{r, v}$ & $t_{r, v, p, n_{0}}$ & $t_{r, v, p, n_{\max }}$ & $q_{b u, r, r}$ & $T_{r, v, p}$ & $h_{s t d, r, v, p}$ & $h_{r, v, p}$ & $q_{r, v, p}^{p n p}$ & inc $c_{r, v, p}$ & outc $_{r, v, p}$ \\
\hline 1 & 1 & 1 & 1 & $5: 00$ & $5: 30$ & 16 & 35 & 15 & 4,36 & 59 & 125.000 & 550.000 \\
\hline 2 & 1 & 1 & 2 & $5: 30$ & $9: 40$ & 16 & 59 & 10 & 7,39 & 625 & 180.000 & 550.000 \\
\hline 3 & 1 & 1 & 3 & $9: 40$ & $12: 50$ & 16 & 50 & 15 & 6,29 & 311 & 155.000 & 550.000 \\
\hline 4 & 1 & 1 & 4 & $12: 50$ & $19: 00$ & 16 & 53 & 10 & 6,68 & 872 & 210.000 & 550.000 \\
\hline 5 & 1 & 1 & 5 & $19: 00$ & $20: 00$ & 16 & 46 & 15 & 5,73 & 108 & 145.000 & 550.000 \\
\hline 6 & 1 & 2 & 1 & $5: 00$ & $7: 00$ & 16 & 41 & 20 & 5,13 & 96 & 70.000 & 550.000 \\
\hline 7 & 1 & 2 & 2 & $7: 00$ & $10: 30$ & 16 & 44 & 15 & 5,44 & 306 & 135.000 & 550.000 \\
\hline 8 & 1 & 2 & 3 & $10: 30$ & $10: 00$ & 16 & 58 & 10 & 7,31 & 1385 & 245.000 & 550.000 \\
\hline 9 & 1 & 2 & 4 & $19: 00$ & $20: 00$ & 16 & 46 & 15 & 5,78 & 114 & 170.000 & 550.000 \\
\hline 10 & 1 & 3 & 1 & $5: 00$ & $9: 40$ & 16 & 42 & 20 & 5,30 & 382 & 120.000 & 550.000 \\
\hline 11 & 1 & 3 & 2 & $9: 40$ & $12: 30$ & 16 & 44 & 15 & 5,51 & 310 & 145.000 & 550.000 \\
\hline 12 & 1 & 3 & 3 & $12: 30$ & $13: 40$ & 16 & 49 & 10 & 6,10 & 149 & 205.000 & 550.000 \\
\hline 13 & 1 & 3 & 4 & $13: 40$ & $20: 00$ & 16 & 50 & 15 & 6,27 & 715 & 180.000 & 550.000 \\
\hline 14 & 2 & 1 & 1 & $6: 00$ & $12: 00$ & 6 & 36 & 20 & 11,84 & 64 & 15.000 & 453.000 \\
\hline 15 & 2 & 1 & 2 & $12: 00$ & $18: 00$ & 6 & 57 & 20 & 18,89 & 48 & 10.000 & 453.000 \\
\hline 16 & 3 & 1 & 1 & $5: 45$ & $8: 00$ & 4 & 17 & 20 & 8,63 & 64 & 55.000 & 256.000 \\
\hline 17 & 3 & 1 & 2 & $8: 00$ & $20: 00$ & 4 & 19 & 15 & 9,59 & 672 & 125.000 & 256.000 \\
\hline 18 & 3 & 1 & 3 & $20: 00$ & $21: 00$ & 4 & 17 & 20 & 8,38 & 35 & 75.000 & 256.000 \\
\hline
\end{tabular}

Table 2.Results Data Processing

\begin{tabular}{|c|c|c|c|c|c|c|c|c|c|}
\hline No & $r$ & $v_{r}$ & $p_{r, v}$ & $\Delta t_{r, v, p}$ & $T_{r, v, p} k r v$ & $m_{r, v, p}^{R i t}$ & $M_{r, v, p}^{R i t}$ & $\frac{q_{r, v, p}^{p n p}}{k_{L F_{r, v, p}}}$ & $\begin{array}{l}c_{r, v, p} \\
(1000)\end{array}$ \\
\hline 1 & 1 & 1 & 1 & 30 & 174 & 2 & 6 & 3 & $(425)$ \\
\hline 2 & 1 & 1 & 2 & 250 & 296 & 25 & 33 & 29 & $(370)$ \\
\hline 3 & 1 & 1 & 3 & 190 & 252 & 13 & 30 & 15 & $(395)$ \\
\hline 4 & 1 & 1 & 4 & 370 & 267 & 37 & 55 & 40 & $(340)$ \\
\hline 5 & 1 & 1 & 5 & 60 & 229 & 4 & 10 & 5 & $(405)$ \\
\hline 6 & 1 & 2 & 1 & 120 & 41 & 6 & 23 & 5 & $(480)$ \\
\hline 7 & 1 & 2 & 2 & 210 & 44 & 14 & 38 & 14 & $(415)$ \\
\hline 8 & 1 & 2 & 3 & 510 & 58 & 51 & 69 & 63 & $(305)$ \\
\hline 9 & 1 & 2 & 4 & 60 & 46 & 4 & 10 & 6 & $(380)$ \\
\hline 10 & 1 & 3 & 1 & 290 & 42 & 15 & 54 & 18 & $(430)$ \\
\hline 11 & 1 & 3 & 2 & 160 & 44 & 11 & 29 & 15 & $(405)$ \\
\hline 12 & 1 & 3 & 3 & 70 & 49 & 7 & 11 & 7 & $(345)$ \\
\hline 13 & 1 & 3 & 4 & 380 & 50 & 26 & 60 & 33 & $(370)$ \\
\hline 14 & 2 & 1 & 1 & 360 & 249 & 18 & 30 & 3 & $(438)$ \\
\hline 15 & 2 & 1 & 2 & 360 & 397 & 18 & 19 & 3 & $(443)$ \\
\hline 16 & 3 & 1 & 1 & 135 & 121 & 7 & 15 & 3 & $(201)$ \\
\hline 17 & 3 & 1 & 2 & 720 & 134 & 48 & 75 & 31 & $(131)$ \\
\hline 18 & 3 & 1 & 3 & 60 & 117 & 3 & 7 & 2 & $(181)$ \\
\hline
\end{tabular}

The MBTP-CPE based on the data obtained [Model (1) + data Table 2] is modelled as follows :

Objective Function (1) to maximize the profit of business Maximize $\quad-425 x_{1,1,1}-370 x_{1,1,2}-395 x_{1,1,3}-\ldots-260 x_{3,1,2}-410 x_{3,1,3}$

Constrain (2) ensure that all departures $\left(x_{r, v, p}\right)$ may be served by company employees $\left(K_{p g w} \cdot q_{p g w} / 2\right)$ while maintaining minimum employment limits $\left(k_{p g w} . q_{p g w} / 2\right)$. The number of bus drivers is known to be 54 people with working hours for 5 - 9 hours per day. With each driver working for 6 days in 1 week. One form of constraint that ensures that all departures can be served by company employees while taking into account the minimum employment limits of employees.

$48,600 \leq 175 x_{1,1,1}+295 x_{1,1,2}+\ldots+256 x_{3,1,2}+256 x_{3,1,3} \leq 87,480$

Constraint (3) Ensures that the number of trips served does not exceed the number of trips in accordance with the existing fleet and corresponds to the number of trips on Minimum Service.

$2 \leq x_{1,1,1} \leq 7 ; 25 \leq x_{1,1,2} \leq 34 ; 13 \leq x_{1,1,3} \leq 31 ; 37 \leq x_{1,1,4} \leq 56 ;$ $4 \leq x_{1,1,5} \leq 11 ; 6 \leq x_{1,2,1} \leq 24 ; 14 \leq x_{1,2,2} \leq 39 ; 51 \leq x_{1,2,3} \leq 71$;

$4 \leq x_{1,2,4} \leq 11 ; 15 \leq x_{1,3,1} \leq 56 ; 11 \leq x_{1,3,2} \leq 30 ; 7 \leq x_{1,3,3} \leq 12$;

$26 \leq x_{1,3,4} \leq 61 ; 18 \leq x_{2,1,1} \leq 30 ; 18 \leq x_{2,1,2} \leq 24 ; 7 \leq x_{3,1,1} \leq 16$ $45 \leq x_{3,1,2} \leq 76$

Constraint (4) Ensure that passengers can be served as per the company's expectations or to ensure that the optimal tripnumber performed exceeds the company's expectations to passengers on each departure.

$x_{1,1,1} \geq 3 ; x_{1,1,2} \geq 29 ; x_{1,1,3} \geq 15 ; x_{1,1,4} \geq 40 ; x_{1,1,5} \geq 5 ; x_{1,2,1} \geq 8 ;$ $x_{1,2,2} \geq 14 ; x_{1,2,3} \geq 63 ; x_{1,2,4} \geq 6 ; x_{1,3,1} \geq 18 ; x_{1,3,2} \geq 15 ; x_{1,3,3} \geq 7 ;$ $x_{1,3,4} \geq 33 ; x_{2,1,1} \geq 22 ; x_{2,1,2} \geq 19 ; x_{3,1,1} \geq 9 ; x_{3,1,2} \geq 53 ; x_{3,1,3} \geq 5$;

Constraint (5) Ensure that the optimum number of trips (xr, v, p) produced is a nonnegative integer.

$$
\begin{aligned}
& x_{1,1,1} \in \mathbb{Z}^{+} \cup\{0\} ; x_{1,1,2} \in \mathbb{Z}^{+} \cup\{0\} ; x_{1,1,3} \in \mathbb{Z}^{+} \cup\{0\} ; \\
& x_{1,1,4} \in \mathbb{Z}^{+} \cup\{0\} ; x_{1,1,5} \in \mathbb{Z}^{+} \cup\{0\} ; x_{1,2,1} \in \mathbb{Z}^{+} \cup\{0\} ; \\
& x_{1,2,2} \in \mathbb{Z}^{+} \cup\{0\} ; x_{1,2,3} \in \mathbb{Z}^{+} \cup\{0\} ; x_{1,2,4} \in \mathbb{Z}^{+} \cup\{0\} ; \\
& x_{1,3,1} \in \mathbb{Z}^{+} \cup\{0\} ; x_{1,3,2} \in \mathbb{Z}^{+} \cup\{0\} ; x_{1,3,3} \in \mathbb{Z}^{+} \cup\{0\} ; \\
& x_{1,3,4} \in \mathbb{Z}^{+} \cup\{0\} ; x_{2,1,1} \in \mathbb{Z}^{+} \cup\{0\} ; x_{2,1,2} \in \mathbb{Z}^{+} \cup\{0\} ; \\
& x_{3,1,1} \in \mathbb{Z}^{+} \cup\{0\} ; x_{3,1,2} \in \mathbb{Z}^{+} \cup\{0\} ; x_{3,1,3} \in \mathbb{Z}^{+} \cup\{0\}
\end{aligned}
$$

Constraint (6) Ensuring that the optimum number of trips generated makes headway value a memorable multiplier of time for passengers, in this case headway at 5-minute increments

$$
\left(x_{r, v, p} \ni h_{r, v, p} \in \text { time }_{\text {easy }}\right) ; \text { time } e_{\text {easy }}=\{5,10,15,20,25,30\}
$$

The MBTP-CPE based on data given is then converted into Model (2) + Data with the following results: 
Objective Function (7) To minimize the y variable

Minimize

$\frac{y_{1,1,1}}{0.000392}+\frac{y_{1,1,2}}{0.000054}+\frac{y_{1,1,3}}{0.000067}+\ldots+\frac{y_{3,1,2}}{0.000267}+\frac{y_{3,1,3}}{0.002035}$

Constrain (8) To ensure the solution is within the employee working span.

$$
\begin{aligned}
& g_{1}\left(\frac{2}{q_{p g w} K p g w}\right) \leq \sum_{r \in R} \sum_{v \in V_{r}} \sum_{p \in P_{v, r}} g_{2}\left(y_{r, v, p}\right)\left(\frac{5}{T W_{r, v, p} \Delta t_{r, v, p}}\right) \leq g_{1}\left(\frac{2}{q_{p g w^{k} p g w}}\right) \\
= & 0.00001 \leq 0.000952 y_{1,1,1}+0.000068 y_{1,1,2}+ \\
& 0.000105 y_{1,1,3}+\ldots+0.000061 y_{3,1,2}+0.000701 y_{3,1,3} \leq \\
& 0.0002
\end{aligned}
$$

Constrain (9) To ensure that the headway obtained is in accordance with the number of available fleets and above the minimum service standards provided.

$1 \leq y_{1,1,1} \leq 3 ; 2 \leq y_{1,1,2} \leq 2 ; 2 \leq y_{1,1,3} \leq 3 ; 2 \leq y_{1,1,4} \leq 2$;

$2 \leq y_{1,2,1} \leq 3 ; 1 \leq y_{1,2,2} \leq 4 ; 2 \leq y_{1,2,3} \leq 3 ; 2 \leq y_{1,2,4} \leq 2$;

$2 \leq y_{1,3,1} \leq 3 ; 2 \leq y_{1,3,2} \leq 4 ; 2 \leq y_{1,3,3} \leq 3 ; 2 \leq y_{1,3,4} \leq 2$;

$2 \leq y_{2,1,1} \leq 3 ; 3 \leq y_{2,1,1} \leq 4 ; 2 \leq y_{2,1,2} \leq 4 ; 2 \leq y_{3,1,1} \leq 4$;

$2 \leq y_{3,1,2} \leq 4 ; 2 \leq y_{3,1,3} \leq 4$

Constrain (10) Ensure that the headway obtained is above the company's expectations of passenger conditions

$y_{1,1,1} \leq 2 ; y_{1,1,2} \leq 2 ; y_{1,1,3} \leq 3 ; y_{1,1,4} \leq 2 ; y_{1,1,5} \leq 3 ; y_{1,2,1} \leq 3$; $y_{1,2,2} \leq 3 ; y_{1,2,3} \leq 2 ; y_{1,2,4} \leq 2 ; y_{1,3,1} \leq 4 ; y_{1,3,2} \leq 3 ; y_{1,3,3} \leq 2$; $y_{1,3,4} \leq 3 ; y_{2,1,1} \leq 4 ; y_{2,1,2} \leq 4 ; y_{3,1,1} \leq 3 ; y_{3,1,2} \leq 3 ; y_{3,1,1} \leq 3$

Constrain (11) Ensure that the resulting solution is an integer of 1 to the number of set members of that number $(|\mathrm{Y}|)$, in which case $\mathrm{Y}=(1,2,3,4,5,6)$;

$1 \leq y_{r, v, p} \in \mathrm{Z}^{+} \leq|Y|, Y=\{1,2,3,4,5,6\} ; \forall r \in R, \forall v \in V_{r}, \forall p \in P_{r, v}$

Completion Model (2) + Data by Branch and Bound Algorithm with the following result.

Table 3. The Result of MBTP-CPE

\begin{tabular}{|c|c|c|c|c|c|}
\hline No & $r$ & $v_{r}$ & $p_{r, v}$ & $y_{r, v, p}$ & Headway \\
\hline 1 & 1 & 1 & 1 & 1 & 5 \\
\hline 2 & 1 & 1 & 2 & 2 & 10 \\
\hline 3 & 1 & 1 & 3 & 2 & 10 \\
\hline 4 & 1 & 1 & 4 & 2 & 10 \\
\hline 5 & 1 & 1 & 5 & 2 & 10 \\
\hline 6 & 1 & 2 & 1 & 1 & 5 \\
\hline 7 & 1 & 2 & 2 & 2 & 10 \\
\hline 8 & 1 & 2 & 3 & 2 & 10 \\
\hline 9 & 1 & 2 & 4 & 2 & 10 \\
\hline 10 & 1 & 3 & 1 & 2 & 10 \\
\hline 11 & 1 & 3 & 2 & 2 & 10 \\
\hline 12 & 1 & 3 & 3 & 2 & 10 \\
\hline 13 & 1 & 3 & 4 & 2 & 10 \\
\hline 14 & 2 & 1 & 1 & 3 & 15 \\
\hline 15 & 2 & 1 & 2 & 3 & 15 \\
\hline
\end{tabular}

\begin{tabular}{|l|l|l|l|l|l|}
\hline 16 & 3 & 1 & 1 & 2 & 10 \\
\hline 17 & 3 & 1 & 2 & 2 & 10 \\
\hline 18 & 3 & 1 & 3 & 2 & 10 \\
\hline
\end{tabular}

Implementation of optimal headway results in the form of time table for Bubulak route - day bar on Monday - Friday $\left(r=1, v_{1}=1\right)$ is as follows :

Table 4. Example of Optimal Bus Time Table

Bus Timetable [Bubulak - Baranang Siang] Monday - Friday

\begin{tabular}{|c|c|c|c|c|c|c|c|c|c|c|c|}
\hline $5: 00$ & $5: 05$ & $5: 10$ & $5: 15$ & $5: 20$ & $5: 25$ & $5: 30$ & $5: 40$ & $5: 50$ & $6: 00$ & $6: 10$ & $6: 20$ \\
\hline $6: 30$ & $6: 40$ & $6: 50$ & $7: 00$ & $7: 10$ & $7 \cdot 20$ & $7 \cdot 30$ & $7: 40$ & $7 \cdot 50$ & $8: 00$ & $8: 10$ & $8: 20$ \\
\hline
\end{tabular} \begin{tabular}{|c|c|c|c|c|c|c|c|c|c|c|c|c|}
\hline $6: 30$ & $6: 40$ & $6: 50$ & $7: 00$ & $7: 10$ & $7: 20$ & $7: 30$ & $7: 40$ & $7: 50$ & $8: 00$ & $8: 10$ & $8: 20$ \\
\hline $8: 30$ & $8: 40$ & $8: 50$ & $9: 00$ & $9: 10$ & $9: 20$ & $9: 30$ & $9: 40$ & $9: 50$ & $10: 00$ & $10: 10$ & $10: 20$ \\
\hline $10: 3$ & $10: 40$ & $10: 50$ & $11: 00$ & $11: 10$ & $11: 20$ & $11: 30$ & $11: 0$ & $11: 0$ & $12: 00$ & $12: 10$ & $12: 0$ \\
\hline
\end{tabular}

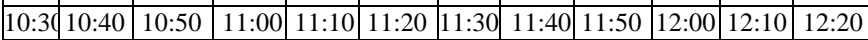

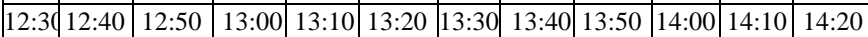

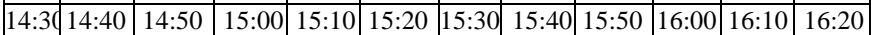

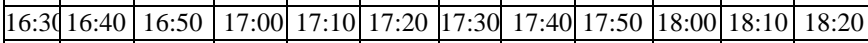
\begin{tabular}{|l|l|l|l|l|l|l|l|l|l|}
\hline $18: 30$ & $18: 40$ & $18: 50$ & $19: 00$ & $19: 10$ & $19: 20$ & $19: 30$ & $19: 40$ & $19: 50$ & $20: 00$ \\
\hline
\end{tabular}

The result of MBTP-CPE sensitivity analysis based on the data obtained was done with five scenarios with the result in the following table. Figure 1 shows the results of sensitivity analysis for the addition of constraints of passenger ease. The

\begin{tabular}{|c|c|c|}
\hline No & Scenarios & Result \\
\hline 1 & $\begin{array}{l}\text { The addition of } \\
\text { Considering Passenger } \\
\text { Ease constraints } \\
\left(\text { time }_{\text {easy }}\right)\end{array}$ & $\begin{array}{l}\text { It directly reduces the number of trips by } \\
\text { nearly } 35 \% \text {. The reduction in the number } \\
\text { of trips also resulted in an increase in the } \\
\text { value of objective function (or decrease in } \\
\text { business losses) by nearly } 40 \%\end{array}$ \\
\hline 2 & $\begin{array}{l}\text { Increasing number of } \\
\text { employees }\end{array}$ & $\begin{array}{l}\text { The addition of the number of employees } \\
\text { will not change the number of bus trips } \\
\text { directly. More and more employees result } \\
\text { in high minimum work limits that result in } \\
\text { low employee workload. }\end{array}$ \\
\hline 3 & $\begin{array}{l}\text { Added the number of } \\
\text { buses }\end{array}$ & $\begin{array}{l}\text { Increasing the number of buses will affect } \\
\text { the time lapse of departures between each } \\
\text { bus (headway) and the maximum limit of } \\
\text { travel thus affecting the number of bus trips } \\
\text { directly. }\end{array}$ \\
\hline 4 & $\begin{array}{l}\text { Increase in the number } \\
\text { of passengers }\end{array}$ & $\begin{array}{l}\text { Increasing the number of passengers } \\
\text { without changing the standard load factor } \\
\text { increases the number of trips to be taken so } \\
\text { that the number of passengers can be } \\
\text { served as per the company's expectations } \\
\text { but does not directly affect the number of } \\
\text { bus trips. }\end{array}$ \\
\hline 5 & $\begin{array}{l}\text { Addition of standard } \\
\text { passenger numbers } \\
\text { (decrease in standard } \\
\text { load factor) }\end{array}$ & $\begin{array}{l}\text { Increasing the number of load factors by } \\
\text { increasing the number of passengers will } \\
\text { result in reduced number of trips to be } \\
\text { made so that the number of passengers can } \\
\text { be served as per the company's } \\
\text { expectations but does not affect the optimal } \\
\text { number of trips directly. The addition of } \\
\text { standard passenger numbers will also affect } \\
\text { the decrease of passenger comfort level. }\end{array}$ \\
\hline
\end{tabular}
image displays for the value of $x^{*}$ (the optimal number of trips) and the $z$ value (total profit for $x^{*}$ ).

Table 5. The Result of (Model (1) + data) Sensitivity Analysis

Published By: 


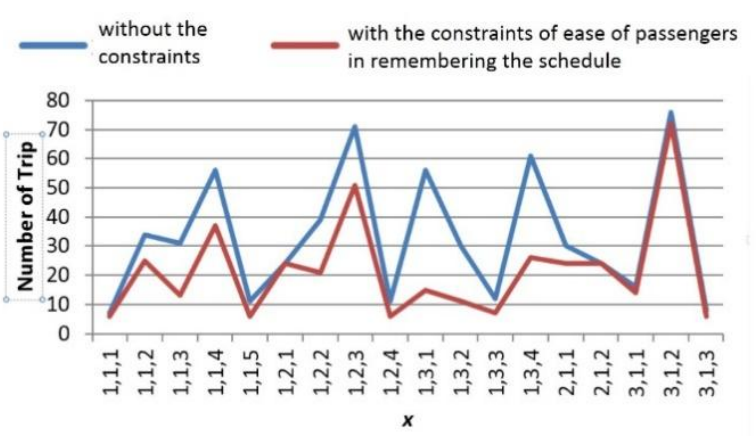

Fig. 1.The results of sensitivity analysis for the addition of constraints of passenger ease to number of trip

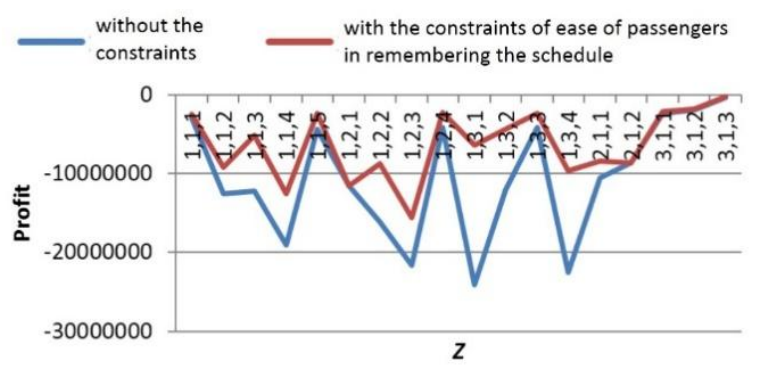

Fig. 2.The results of sensitivity analysis for the addition of constraints of passenger ease to profit

\section{CONCLUSION}

The Model Bus Timetabling Problem by Considering Passenger Ease was successfully implemented on Bogor's Bus Rapid Transit System. The optimal number of trip for each route will affect the time lapse of departure between each bus (headway), so it will also find the optimal bus time table. Sensitivity analysis on the addition of any scenarios of possible changes results in different effects, for the addition of scenarios of obstacles to the disorder will reduce the optimal trip number and reduce the losses, for the increment scenario the number of employees will affect the hours of work of the employees every day and every week ,for the scenario adding the number of buses will affect the optimal number of trip, for the scenario of increasing the number of passengers and the number of passengers served according to the Minimum Service Standards will only affect the minimum number of trip that must be taken for each departure route.

\section{REFERENCES}

1. F. D. Wihartiko, A. Buono and B. P. Silalahi. "Integer programming model for optimizing bus timetable using genetic algorithm." IOP Conference Series: Materials Science and Engineering. Vol. 166, no. 1, pp. 1-9, 2017.

2. R. Kujala, C. Weckström R. K. Darst, M. N. Mladenović and J. Saramäki. "Data Descriptor: A collection of public transport network data sets for 25 cities." Scientific Data, vol. .5, art. no. 180089, 2018.

3. L. Tian Z. Yunjiao and Z. Jianyou. "Application of GPS Based Inttelligent Dispatching System in Public Transportation.” Revista Ibérica de Sistemas e Tecnologias de Informação, vol. (18B), art. no. 237, 2016.
4. X. Shen S. Feng, Z. Li and B. Hu. "Analysis of bus passenger comfort perception based on passenger load factor and in- vehicle time." SpringerPlus, vol. 5, no. 1, art. no. 62, 2016.

5. A. Cedar, B. Golany and O. Tal. "Creating Bus Timetables with Maximal Syncronization.” Transportation Research Part A: Policy and Practice, vol. 35, no. 10, pp. 913-928, 2001.

6. V. Naumov. "Synchronisation of Timetables for Public Bus Lines Using Genetic Algorithms and Computer Simulations." Lecture Notes in Networks and Systems, vol 36, pp. 44-53, 2018.

7. S. Chuanjiao, Z. Wei and W. Yuanqing. "Scheduling Combination and Headway Optimization of Bus Rapid Transit." Journal of Transportation Systems Engineering and Information Technology. vol. 8 , no. 5 , pp. $61-67,2008$.

8. N. S. Bais, N. Pitale and S. Thorat. "Optimal Schedule Modeling for Public Transportasi System.” International Journal of Science and Research vol. 4, no. 4, 2015.

9. H. Mayyani, B. P Silalahi and A Aman. "Frequency Determination of Bus Rapid Transit (BRT) Applied on Service System of Trans Mataram Metro Bus to Minimize the Operational Cost." International Journal of Engineering and Management Research. vol. 7, no. 6, pp. 134-140, 2017.

10. J. Ma, Y. Zhao, Y. Yang, T. Liu, W. Guan, J. Wang and C. "A Model for the Stop Planning and Timetables of Customized Buses.” Plos One. Vol. 12, no. 1, art. no. e0168762, 2017.

11. F. D. Wihartiko, H. Wijayanti and F. Virgantari. "Performance Comparison of Genetic Algorithms and Particle Swarm Optimization for Model Integer Programming Bus Timetabling Problem." IOP Conference Series: Materials Science and Engineering. vol. 332, art. no. $012020,2018$. 